\title{
The Association between miR-196a2 rs11614913 Polymorphism and Digestive System Cancer Risk: A Meta-Analysis of 34 Studies
}

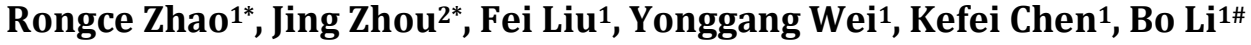 \\ ${ }^{1}$ Department of Liver Surgery and Liver Transplantation Center, West China Hospital, Sichuan University, Chengdu, China \\ ${ }^{2}$ Department of Medical Oncology, Cancer Center, State Key Laboratory of Biotherapy, West China Hospital, Sichuan University, \\ Chengdu, China \\ Email: zhaorongce@163.com, zzuzj2008@163.com, 182310227@qq.com,yourwyg@163.com,ckf2003@163.com, \\ "cdlibo168@hotmail.com
}

How to cite this paper: Zhao, R.C., Zhou, J., Liu, F., Wei, Y.G., Chen, K.F. and Li, B. (2016) The Association between miR-196a2 rs11614913 Polymorphism and Digestive System Cancer Risk: A Meta-Analysis of 34 Studies. Open Journal of Internal Medicine, 6, 112-127.

http://dx.doi.org/10.4236/ojim.2016.64017

Received: September 29, 2016

Accepted: November 27, 2016

Published: November 30, 2016

Copyright $\odot 2016$ by authors and Scientific Research Publishing Inc. This work is licensed under the Creative Commons Attribution International License (CC BY 4.0).

http://creativecommons.org/licenses/by/4.0/

\section{(c) (i) Open Access}

\begin{abstract}
Background: MicroRNAs (miRNAs) negatively regulate the gene expression and act as tumor suppressors or oncogenes in carcinogenesis. The association between single nucleotide polymorphism (SNP) in miR-196a2 rs11614913 and the susceptibility of digestive system cancers was inconsistent in previous studies. Methods: A standardized search of PubMed, Embase, and Cochrane library databases for publications on miR-196a2 rs11614913 polymorphism and digestive system cancer risk was performed. Then the genotype data were analyzed in a meta-analysis. Odds ratios (ORs) with 95\% confidence intervals (CIs) were calculated to evaluate the association. Test of heterogeneity, sensitivity analysis and assessment of publication bias were conducted in the present meta-analysis by STATA software 12.0. Results: An updated metaanalysis based on 34 independent case-control studies consisting of 13,013 cases and 16,046 controls was performed to address this association. There was a remarkable association between miR-196a2 rs11614913 polymorphism and overall digestive system cancer risk, especially in Asian populations. Moreover, subgroup analysis revealed that variant $C$ allele increased risk of colorectal carcinoma, gastric cancer and hepatocellular carcinoma (HCC), compared with wild T allele. Conclusions: There was a remarkable association between miR-196a2 rs11614913 polymorphism and overall digestive system cancer risk, especially in Asian populations.
\end{abstract}

\section{Keywords}

miR-196a2, rs11614913, Polymorphism, Digestive System Cancers, Meta-Analysis

${ }^{\star}$ These authors contributed equally to this work. 


\section{Introduction}

MicroRNAs (miRNAs) are a kind of evolutionarily highly conserved, non-coding, single-stranded RNAs with the length of about 22 nucleotides (nt). MiRNAs play crucial roles in a board range of biological processes, including cell differentiation, proliferation, apoptosis and carcinogenesis [1]. The miRNAs regulate the expression of approximately $10 \%-30 \%$ of all human genes through post-transcriptional mechanism pairing to 3'-untranslated region (3'UTR) of target messenger RNA (mRNA), leading to mRNA degradation or translational repression [2]. Accumulating studies have demonstrated that this novel kind of gene regulators got involved in cancer-related process [3]. The loss and gain of function of some specific miRNAs were also considered to be crucial events in diverse cancers [4]. Although the precise mechanism of how miRNAs mediate carcinogenesis still remains ambiguous, genetic alterations of miRNAs are supposed to be a key event [5].

Single-nucleotide polymorphisms (SNPs) are defined as variation of a single nucleotide (A, T, C, or G) in DNA sequence that occurs at least $1 \%$ in certain populations. As the most common type of variation in the human genome, SNPs can influence the population diversity, disease susceptibility, and individual response to medicine by affecting sequence coding and splicing [6]. SNPs in miRNA-coding genes may affect processing and binding ability of miRNAs by altering the secondary structure of miRNA precursors, resulting in aberrant expression of a series of target genes and contributing to cancer susceptibility [7]. Hu et al. [8] first reported that SNP miR196a2 rs11614913 was associated to non-small cell lung cancer survival and the CC genotype presented a significant correlation with mature has-mir-196a expression but not with changes in levels of its precursor, suggesting that the process of the pre-miRNA to its mature form was enhanced. Hoffman et al. [9] found that rs11614913 not only has an impact on the level of mature miR-196a, but also influences the expression of target genes. Numerous epidemiological studies have demonstrated the association of SNPs in miRNAs with the development and progression of cancer [7] [10]. Furthermore, the association between hsa-miR-196a2 rs11614913 polymorphism and cancer risk has been analyzed in several studies, but the conclusions of these studies remain inconsistent due to heterogeneity of the cancer subtype, limited sample size, and differences in the ethnicity of patients. To reduce the potential between-study heterogeneity which might derive from various cancers in diverse systems and improve the efficiency of meta-analysis on digestive cancers, we only focused on digestive system cancers. Therefore, we conducted this meta-analysis to derive a more precise estimation of the association of miR-196a2 rs11614913 with digestive system cancer risk.

\section{Materials and Method}

\subsection{Publication Search}

To identify all potentially eligible studies, we conducted a comprehensive literature search in PubMed, Embase, and Cochrane library databases between 2000 and Sep- 
tember 2016 (last updated on September 21st, 2016) with the following search strategy: "miR-196a2 or microRNA-196a2 or rs11614913"; "SNP or polymorphism or mutation or variant or allele" and "cancer or tumor or carcinoma or neoplasm". The references of retrieved articles were also screened to search other potentially related articles. Studies containing two or more case-control groups were considered as two or more independent studies.

\subsection{Selection Criteria}

Eligible studies were selected according to the following explicit inclusion criteria: I) evaluation of miR-196a2 polymorphism and digestive system cancer risk; II) independent case-control studies for human; III) sufficient published data for calculating odds ratios (ORs) with their 95\% confidence intervals (95\% CIs); IV) cases with carcinomas were diagnosed by histopathology; V) published in English or Chinese.

\subsection{Data Extraction Methodological Assessment}

Two investigators (Zhao and Zhou) independently extracted information from eligible studies using a standardized data collection protocol: first author's name, year of publication, country of origin, ethnicity, cancer type, genotyping method, source of control groups, whether verified Hardy-Weinberg equilibrium (Table 1), $\mathrm{C}$ allele frequency in controls, and genotype frequency distribution. If original genotype frequency data was unavailable in relevant articles, a request for additional data was sent to the corresponding author. Disagreements were resolved by discussion between the two investigators.

The same authors evaluated the methodological quality of the included studies using the Newcastle-Ottawa Scale (NOS) criteria, independently [11]. The NOS criteria are scored based on three aspects: 1) subject selection: $0-4,2$ ) comparability of subject: 0 - 2, and 3) clinical outcome: 0 - 3. Total NOS scores ranged from 0 to 9 , with scores $\geq 7$ indicating good quality.

\subsection{Statistical Analysis}

Hardy-Weinberg equilibrium (HWE) in control subjects was tested by the Chi-square goodness-of-fit test. It was considered to be a state of disequilibrium with P-value less than 0.05 . Crude ORs and 95\% CIs were used to assess the strength of the association between the miR-196a2 rs11614913 polymorphism and digestive system cancer risk. The pooled ORs were calculated for homozygote comparison (CC vs.TT), heterozygote comparison (CC vs. CT), dominant model (CC + CT vs.TT), recessive model (CC vs. $\mathrm{CT}+\mathrm{TT}$ ) and allele model ( $\mathrm{C}$ vs. $\mathrm{T}$ ), respectively. Subgroup analyses were also conducted by cancer type, ethnicity (Caucasian and Asian), source of control (populationbased and hospital-based), and HWE in controls. The significance of the pooled OR was determined by the $\mathrm{Z}$ test in which $\mathrm{P}$ value $<0.05$ was considered statistically significant.

We used chi-square-based Q-test and the $\mathrm{I}^{2}$ index to determine the heterogeneity 
Table 1. Characteristics of included studies.

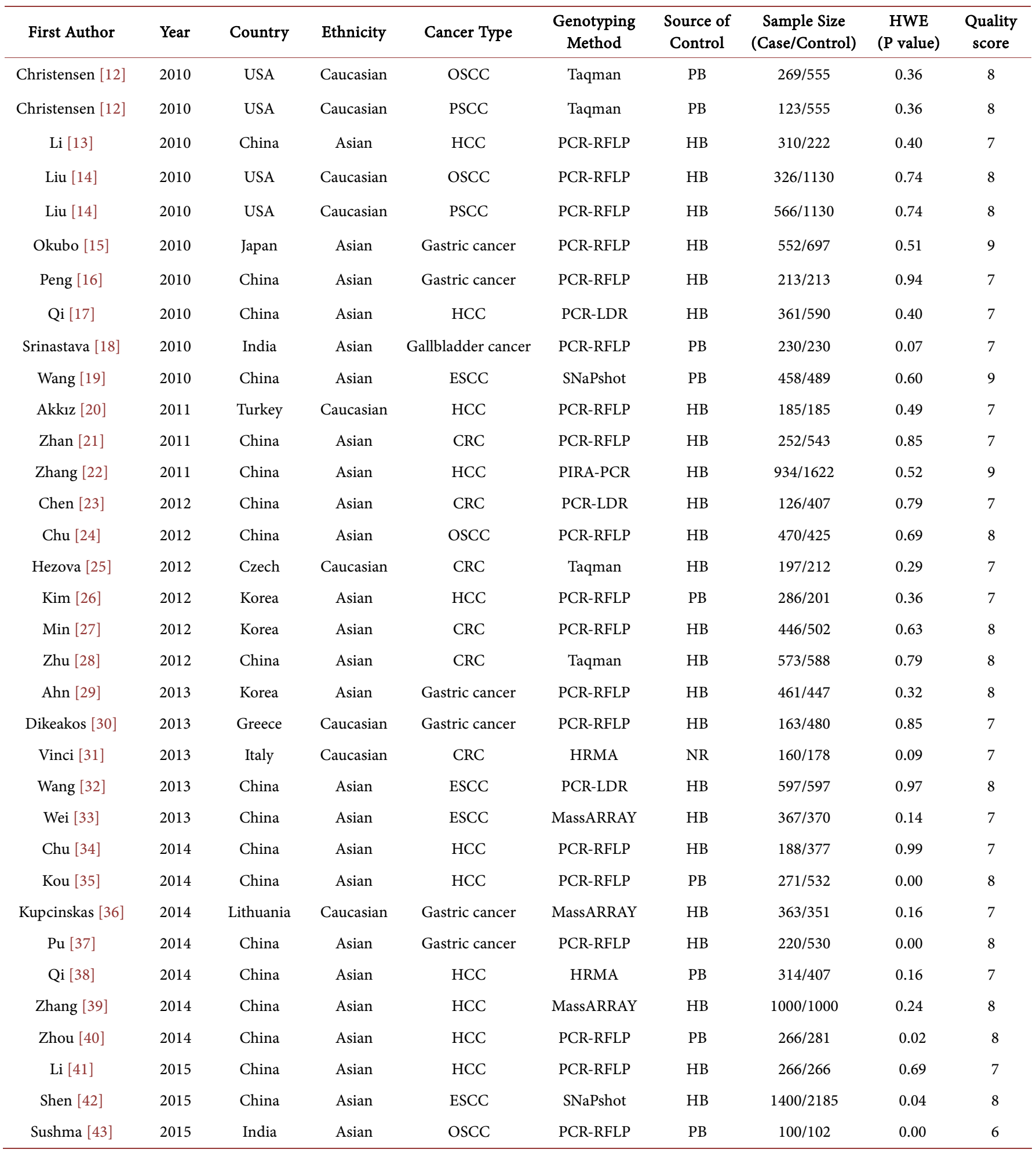

OSCC: oral squamous cell carcinoma, PSCC: pharynx squamous cell carcinoma, HCC: hepatocellular carcinoma, ESCC: esophageal squamous cell carcinoma, CRC: colorectal cancer, PCR-RFLP: polymerase chain reaction-restriction fragment length polymorphism, PCR-LDR: polymerase chain reaction-ligation detection reaction, PIRA-PCR: primer-introduced restriction analysis-polymerase chain reaction, HRMA: high-resolution melting analysis, PB: population-based, HB: hospital-based, NR: not reported, HWE: Hardy-Weinberg equilibrium of controls. 
among different studies. The Galbraith plot was used to detect the potential sources of heterogeneity. The random-effect model was used when heterogeneity was considered significant ( $\mathrm{P}$-value $<0.10$ and/or $\mathrm{I}^{2}$ index $\left.>50 \%\right)$; otherwise, the fixed-effects model was conducted. In addition, potential publication bias was evaluated using Begg's funnel plot, Begg's test and Egger's test. Asymmetric funnel-shaped plots or $\mathrm{P}<0.05$ was considered the existence of publication bias. We conducted one-way sensitivity analysis to assess the stability of the results. One single study was excluded each time to reflect the influence of the individual data set to the pooled ORs.

All statistical analyses were carried out with STATA software version 12.0 (STATA Corp, College Station, TX). All the P values were two-sided.

\section{Results}

\subsection{Studies Characteristic}

In total, 32 eligible studies [12]-[43] including 34 data sets were collected according to the inclusion criteria, with 13013 cases and 16046 controls (Figure 1). Characteristics of these studies were shown in Table 1. Among Christensen et al. and Liu et al.'s studies [12] [14] on head and neck squamous cell carcinoma (HNSCC, which included oral, pharyngeal and laryngeal cancers), oral and pharyngeal cancers in digestive system were included, while laryngeal cancer in respiratory system was not used. Oral cancer and pharyngeal cancer were considered as separate groups and calculated independently.

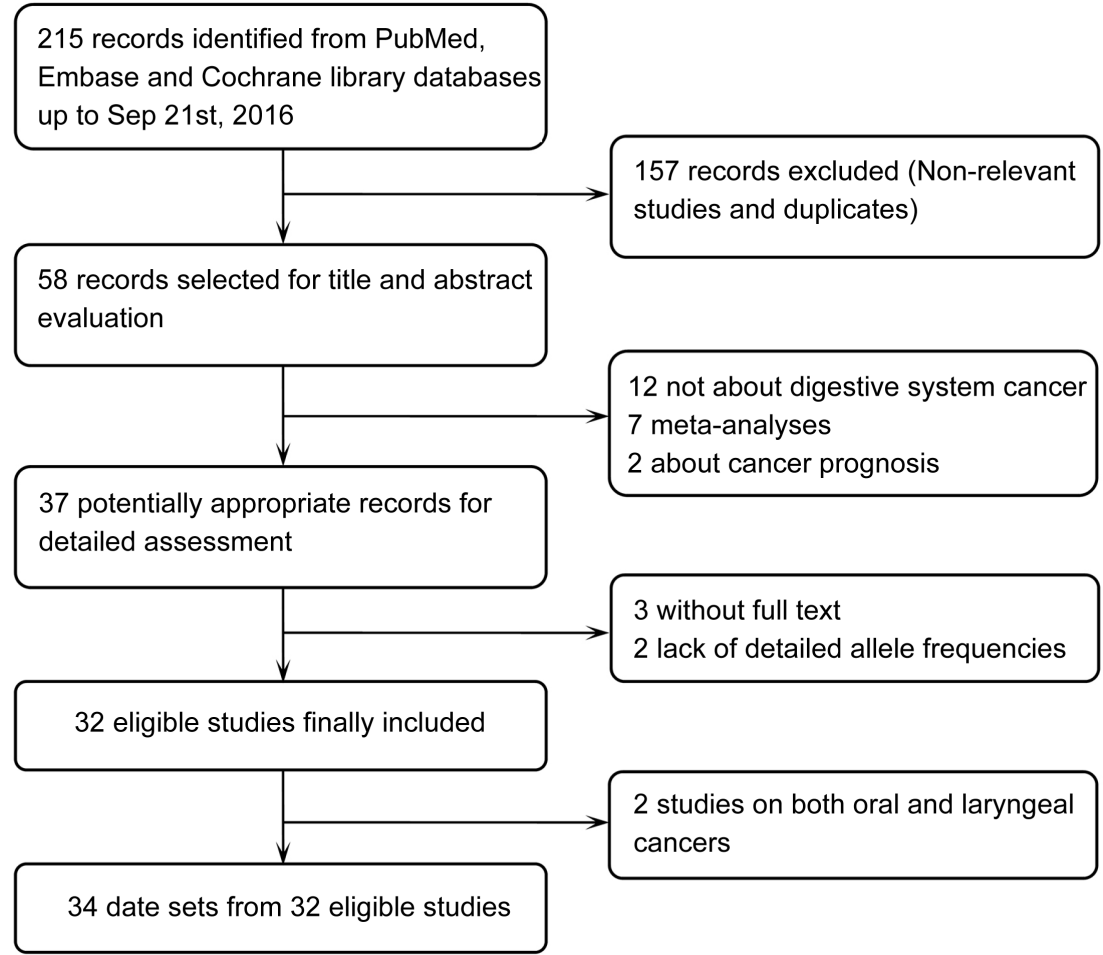

Figure 1. Flow chart of study selection. 
Of all the including studies, 4 were on oral squamous cell carcinoma (OSCC), 2 were on pharyngeal squamous cell carcinoma (PSCC), 11 were on hepatocellular carcinoma (HCC), 6 were on gastric cancer (GC), 1 was on gallbladder cancer (GBC), 4 were on esophageal squamous cell carcinoma (ESCC), and 6 were on colorectal carcinoma (CRC). The subjects of 25 studies were Asian and the other 9 studies were Caucasian. Matching for age and sex, controls of 25 studies were hospital-based and 9 studies were population-based. Genotype distribution of controls in most studies was in agreement with HWE (Table 1).

\subsection{Quantitative Synthesis}

The association strength of miR-196a2 rs11614913 polymorphism and the susceptibility for digestive system cancers is presented in Table 2.

Significant association between miR-196a2 rs11614913 polymorphism and the risk of digestive system cancers were observed in all comparisons (CC vs.TT: OR $=1.317$, 95\%CI $1.119-1.1 .549$; CT vs.TT: OR $=1.163,95 \%$ CI $1.057-1.279$; CC + CT vs. TT: $\mathrm{OR}=1.219,95 \% \mathrm{CI} 1.095-1.357$; CC vs. CT + TT: OR $=1.164,95 \% \mathrm{CI} 1.013-1.337 ; \mathrm{C}$ vs. T: OR $=1.139,95 \% \mathrm{CI} 1.047-1.240$ ).

Cancer types, source of controls, ethnicity and HWE in controls were taken into consideration for subgroup analysis (Table 2). The forest plot of dominant model (CC + CT vs. TT) in different cancer types is shown in Figure 2. In the stratified analysis by cancer type, remarkable association was detected in Colorectal carcinoma (CC vs. TT: $\mathrm{OR}=1.325,95 \% \mathrm{CI} 1.102-1.594 ; \mathrm{CC}+\mathrm{CT}$ vs. TT: OR $=1.193,95 \% \mathrm{CI} 1.027-1.386$ ), Gastric carcinoma (CT vs. TT: OR $=1.189,95 \% \mathrm{CI} 1.017-1.389$; CC + CT vs. TT: OR = 1.475, 95\%CI $1.007-2.162$ ) and HCC (CC vs. TT: OR = 1.302, 95\%CI $1.019-1.663$; C vs. $\mathrm{T}: \mathrm{OR}=1.13095 \% \mathrm{CI} 1.004-1.272)$. However, no association was found in other types of cancers. In subgroup analysis by ethnicity, significant increased risk was found in Asians (CC vs. TT: OR $=1.253,95 \% \mathrm{CI} 1.081-1.451$; CT vs. TT: $\mathrm{OR}=1.14095 \% \mathrm{CI}$ $1.032-1.260 ; \mathrm{CC}+\mathrm{CT}$ vs.TT: $\mathrm{OR}=1.179,95 \% \mathrm{CI} 1.067-1.304 ; \mathrm{C}$ vs. $\mathrm{T}: \mathrm{OR}=1.109$ 95\%CI 1.035 - 1.188), but not in Caucasians. In subgroup analysis according to source of control, significant increased risk was observed in both hospital-based studies (CC vs. TT: $\mathrm{OR}=1.232,95 \% \mathrm{CI} 1.026-1.478$; CT vs. TT: $\mathrm{OR}=1.02895 \% \mathrm{CI} 1.017-1.201$; $\mathrm{CC}+\mathrm{CT}$ vs. TT: $\mathrm{OR}=1.150,95 \% \mathrm{CI} 1.033-1.280 ; \mathrm{C}$ vs. T: $\mathrm{OR}=1.11295 \% \mathrm{CI} 1.007-$ 1.228 ) and population-based studies (CC vs. TT: $\mathrm{OR}=1.630,95 \% \mathrm{CI} 1.148-2.314$; CC + CT vs.TT: $\mathrm{OR}=1.480$ 95\%CI 1.104-1.983; C vs. T: OR = 1.225, 95\%CI $1.049-1.431$ ). When stratified by HWE status, significant increased risk was found in studies consistent with HWE (CC vs. TT: OR $=1.252,95 \% \mathrm{CI} 1.041-1.505$; CT vs.TT: OR $=1.171$ 95\%CI $1.049-1.307 ; \mathrm{CC}+\mathrm{CT}$ vs. TT: OR $=1.203,95 \% \mathrm{CI} 1.063-1.361 ; \mathrm{C}$ vs. $\mathrm{T}: \mathrm{OR}=$ $1.11195 \% \mathrm{CI} 1.009-1.224$ ), as well as studies not (CC vs. TT: OR $=1.31795 \% \mathrm{CI} 1.119$ 1.549; CC + CT vs. TT: OR $=1.179,95 \% \mathrm{CI} 1.114-1.243$; CC vs. CT + TT: OR $=1.501$ 95\%CI $1.169-1.927$; $\mathrm{C}$ vs. T: OR $=1.30495 \% \mathrm{CI} 1.089-1.562$ ).

\subsection{Evaluation of Heterogeneity}

Heterogeneity between studies was observed in overall comparisons (data not shown). 
Table 2. Meta-Analysis of miR-196a2 rs11614913 polymorphism and digestive system cancer risk.

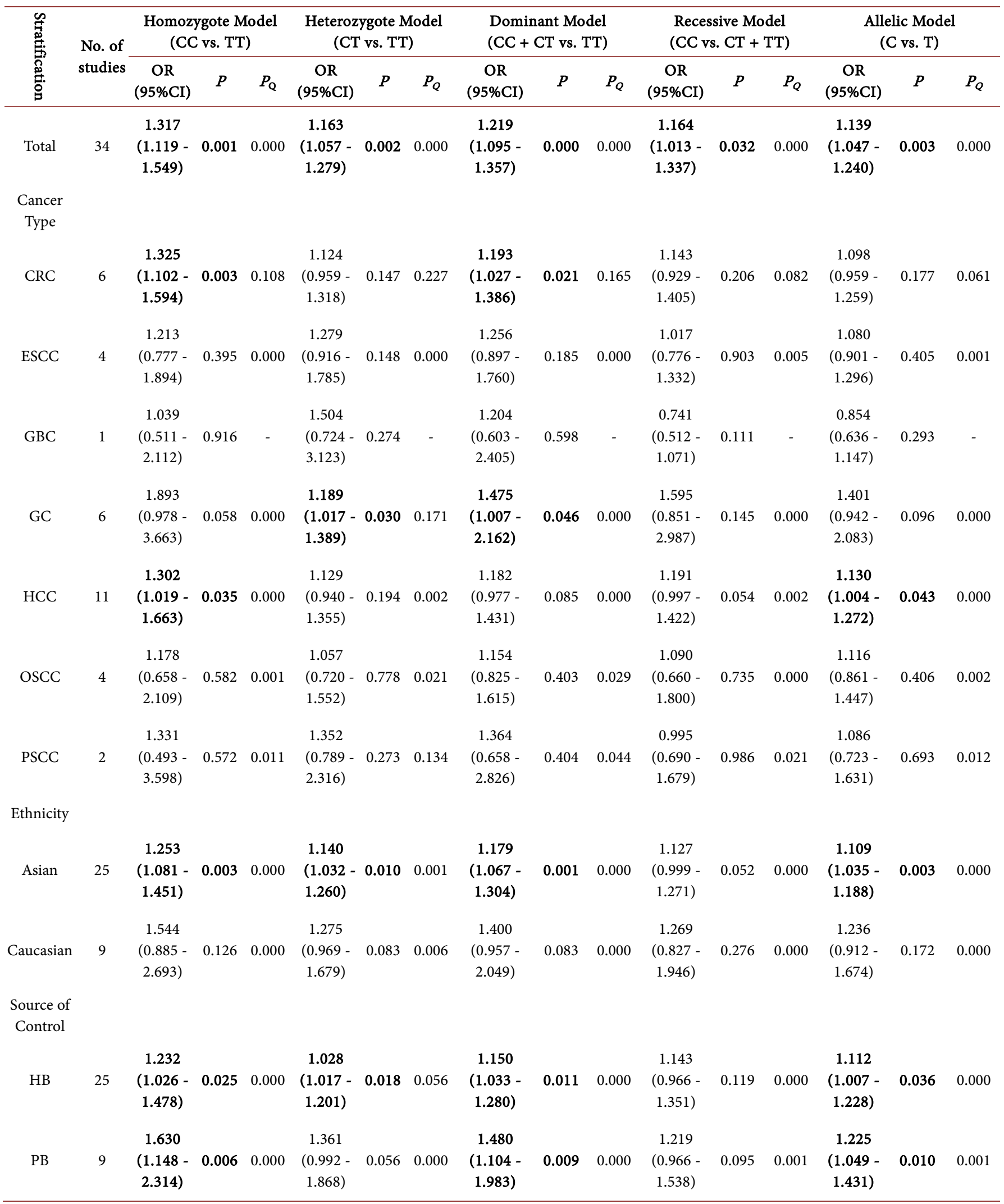


Study

$\%$

ID

OR $(95 \% \mathrm{Cl})$

Weight

oscC

Christensen (2010)

Liu (2010)

Chu (2012)

Sushma (2015)

Subtotal $(\mid-$ squared $=66.7 \%, p=0.029$ )

PSCC

Christensen (2010)

Liu (2010)

Subtotal $(\mid-$ squared $=75.4 \%, p=0.044)$

$\mathrm{HCC}$

Li (2010)

Qi (2010)

Akkiz (2011)

Zhang (2011)

Kim (2012)

Chu (2014)

Kou (2014)

Qi (2014)

Zhang (2014)

Zhou (2014)

Li (2015)

Subtotal $(I-$ squared $=70.1 \%, p=0.000)$

Gastric cancer

Okubo (2010)

Peng (2010)

Ahn (2013)

Dikeakos (2013)

Kupcinskas (2014)

$\mathrm{Pu}$ (2014)

Subtotal $(\mid-$ squared $=82.8 \%, p=0.000)$

Gallbladder cancer

Srivastava (2010)

Subtotal (I-squared $=. \%, p=$.)

ESCC

Wang (2010)

Wang (2013)

Wei (2013)

Shen (2015)

Subtotal $(\mid-$ squared $=85.5 \%, p=0.000)$

CRC

Zhan (2011)

Chen (2012)

Hezova (2012)

$\operatorname{Min}(2012)$

Zhu (2012)

Vinci (2013)

Subtotal $(\mid-$ squared $=36.3 \%, p=0.165)$

Overall ( $I$-squared $=69.0 \%, p=0.000$ )

NOTE: Weights are from random effects analysis

$$
0.103
$$

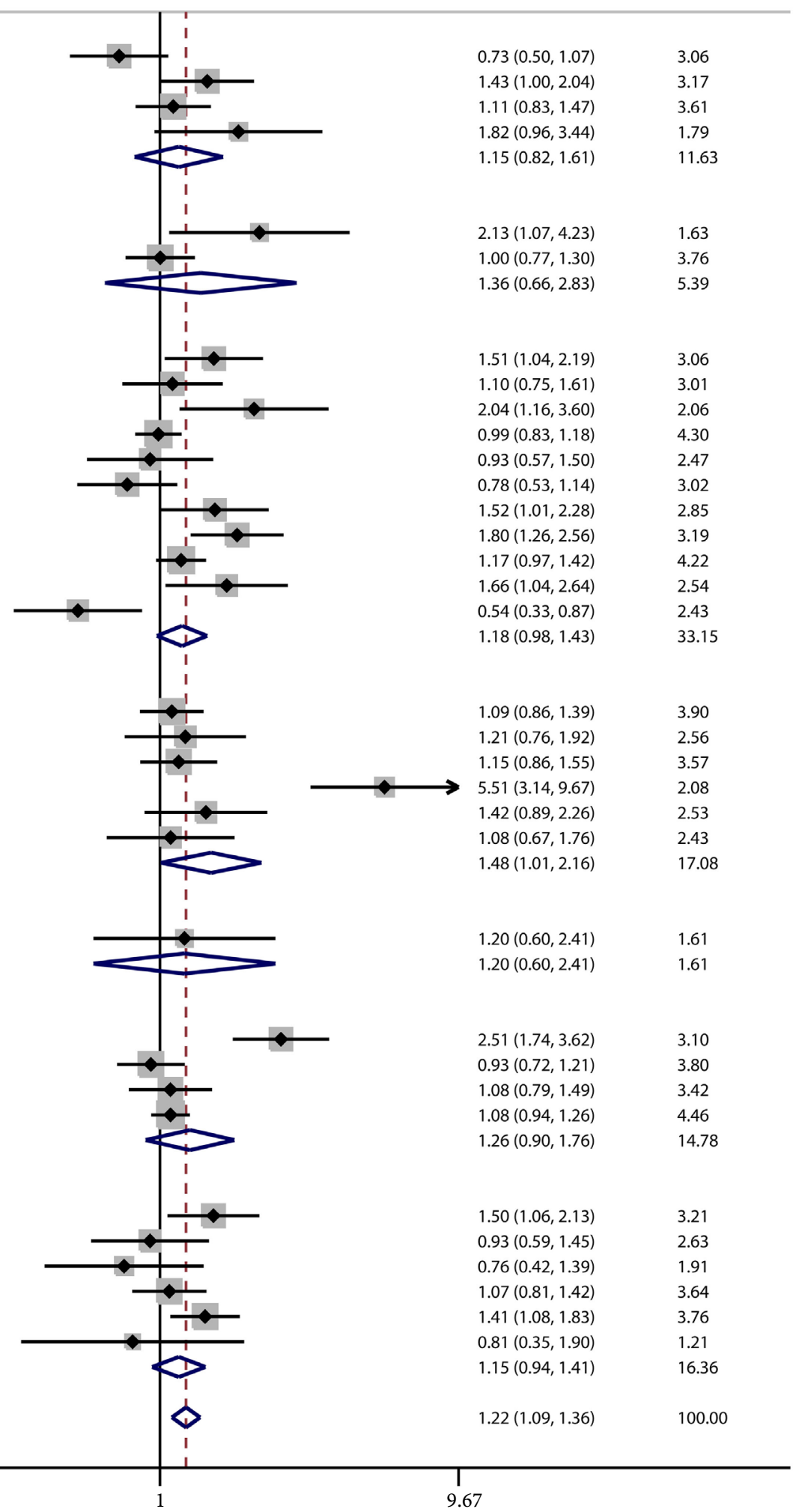

Figure 2. Forest plot of digestive system cancer risk in different cancer types associated with miR-196a2 rs11614913 polymorphism for dominant model (CC + CT vs. TT). 


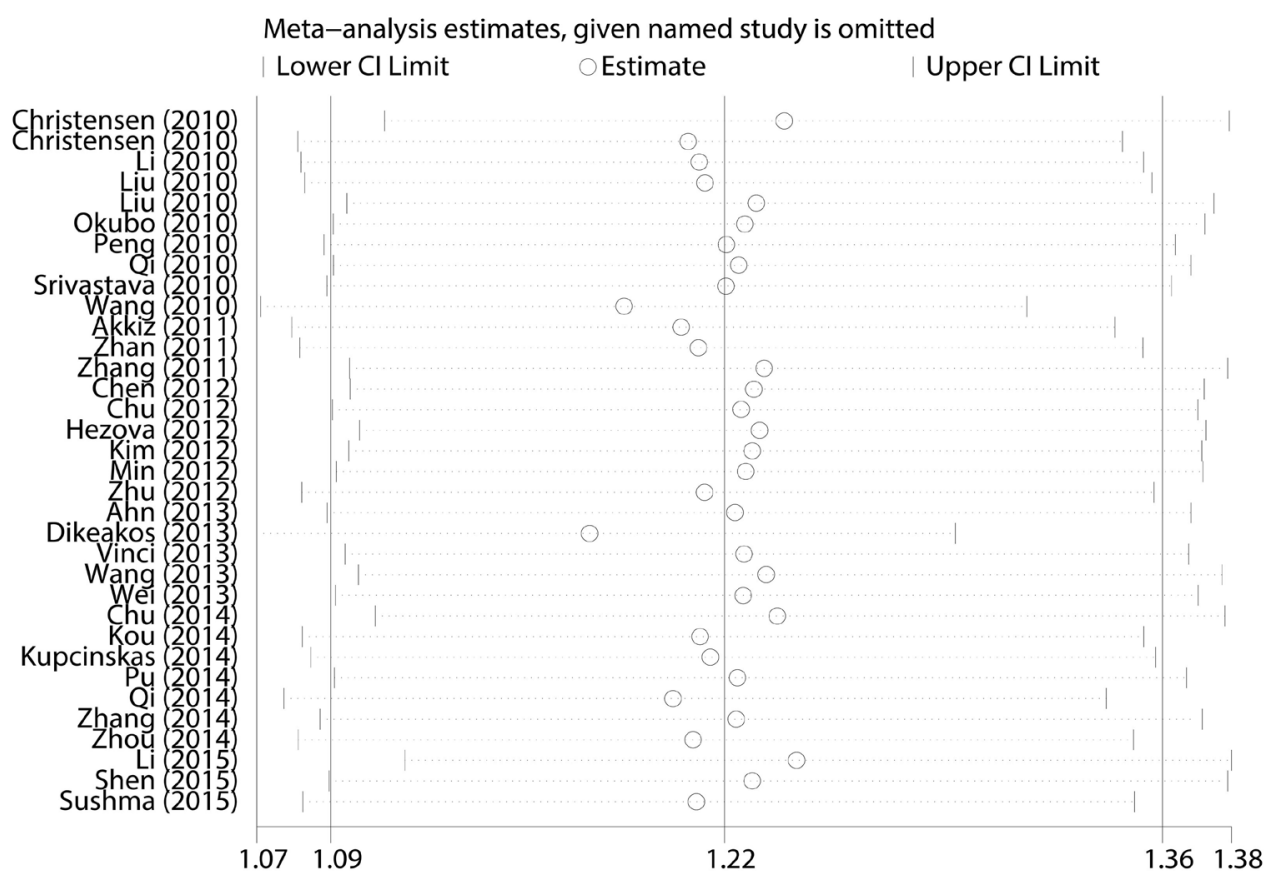

Figure 3. The influence of individual study on the pooled OR for dominant model (CC + CT vs. TT). The middle vertical axis indicates the overall OR and the two vertical axesindicate its 95\%CI. Every circle indicates the pooled OR when the left study is omitted in this meta-analysis. The two ends of every broken line represent the $95 \% \mathrm{CI}$.

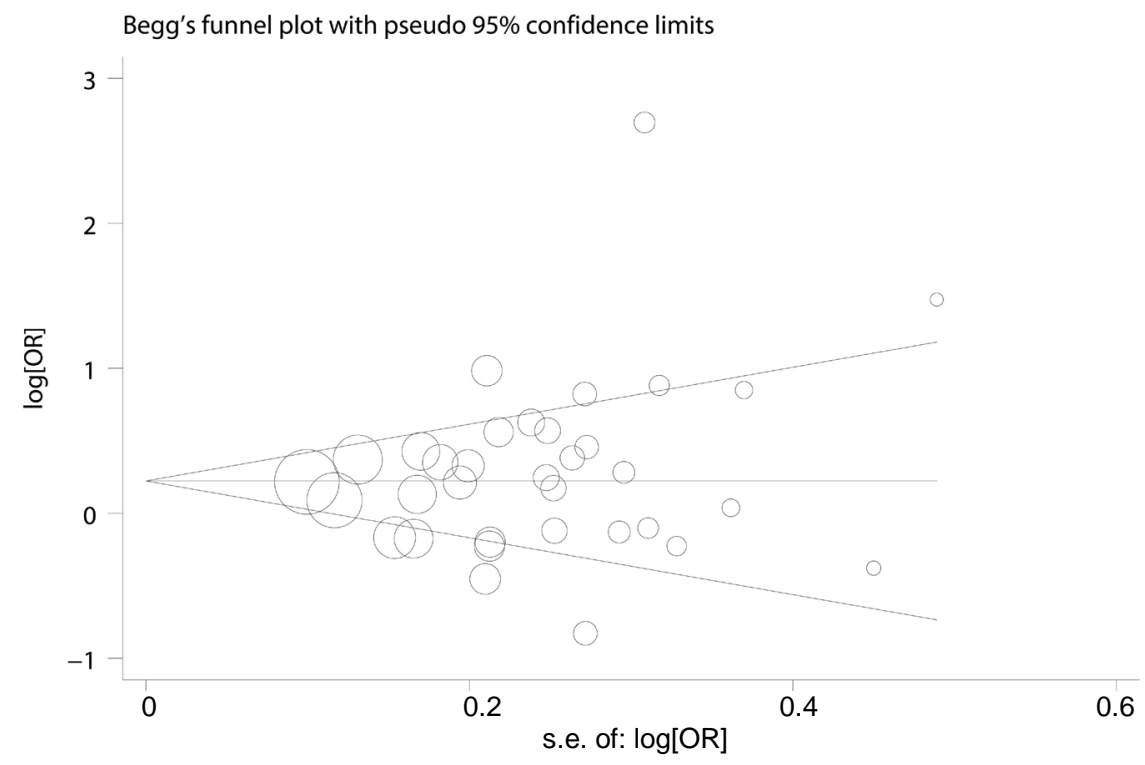

Figure 4. Begg's funnel plot for publication bias test in dominant model (CC + CT vs.TT). Each point represents a separate study for the indicated association. $\log (\mathrm{OR})$ : nature logarithm of OR. Horizontal line represents size of effect. OR: odds ratio.

$1.40,95 \% \mathrm{CI}=1.09-1.79$; respectively). On the contrary, Du et al. [46] found that carriers of CC genotype had a significantly decreased risk for renal cell cancer, compared with the carriers of CT/TT genotype. 
Moreover, several meta-analyses have been conducted on the association between SNPs in miR196a2 and cancer risk, but a unanimous conclusion still has not been achieved. Given the controversial result, we performed this meta-analysis to clarify the association of this variant with digestive system cancer risk. Compared to Guo et al.'s meta-analysis published in 2011 [47], we included another 19 studies, which kept our results more stable and authentic.

In the present meta-analysis, we observed a significant association between rs 11614913 and increased risk in digestive system cancers. However, when stratified by cancer type, rs11614913 merely displayed relevance with CRC, HCC and gastric cancer. This may be explained by the effect of gene polymorphism on cancer susceptibility varies by specific cancer type. Otherwise, the relatively small amount of eligible studies in stratified analysis might induce statistically significant or insignificant association by chance due to insufficient statistical power [48]. In addition, we observed that rs11614913 polymorphism presented a risk factor in Asians, but not in Caucasians. The inconsistent results among different ethnicities may be due to diverse heredity backgrounds. And relatively small number of eligible studies with only 8 Caucasian studies included may be insufficient to detect statistical significance. Therefore, the results from the Caucasian subgroup should be treated with caution. Additional studies, especially Caucasians studies are urgently needed to further validate the ethnic differences in the effect of rs11614913 on digestive system cancer risk. Significant association was observed in both subgroups when stratified by source of control and HWE, which exactly supports the conclusion that rs11614913 polymorphism contribute to the susceptibility of digestive system cancers.

One of the major concerns in a sound meta-analysis is the stability of results, which is examined by sensitivity analysis. The pooled ORs kept unaltered during the sensitivity analysis. When excluding the studies that were inconsistent with HWE, the estimated pooled ORs still did not change at all, indicating that our results are reliable and robust.

Heterogeneity is a major problem that can distort the findings in meta-analysis. Obvious heterogeneity between studies was observed in overall comparisons and most subgroup analyses. In an attempt to find the sources of heterogeneity, a Galbraith plot was drawn (data not shown), and Dikeakos et al.'s study [30] was thought to serve as the main contributor for the heterogeneity. But the heterogeneity still kept considerable after excluding it, indicating that there may have other reasons for the heterogeneity. Then we conducted stratified analysis to reduce heterogeneity, but we found that the variable ethnicity, source of controls, and HWE status could not explain heterogeneity. Notably, in the current study, only studies published in English or Chinese were included, which may partially explain the intractable heterogeneity. Another important problem for any meta-analysis is publication bias due to selective publication of reports. In this meta-analysis, both the shape of funnel plots and statistical results did not show publication bias, suggesting reliability of our study.

Nevertheless, some limitations of this meta-analysis should be addressed. Firstly, oncogenesis is influenced by various factors such as genetic factors, tumor biological 
characteristics environmental damage, while we only focused on the variant in miRNAs. Secondly, our analysis was limited to Asian and Caucasian ethnicities, which limited the general application of the findings from the meta-analysis. Thirdly, only studies published in English and Chinese were included in our meta-analysis. The exclusive reliance on English and Chinese studies may not represent all of the evidence. Excluding languages other than English or Chinese may introduce a language bias and lead to erroneous conclusions. In addition, many studies with negative data, such as absence of links to cancer risks and progression, are most times not considered for submission by researchers, resulting in unavoidable bias. But fortunately, our results of publication bias test show this bias is limitable and acceptable.

\section{Conclusion}

In summary, our meta-analysis reveals that miR196a2 rs11614913 polymorphism contributes to increased digestive system cancer susceptibility, especially in Asian populations. Further, well-designed studies with diverse ethnic groups and larger sample size are required to validate this association.

\section{Acknowledgements}

This study was supported by "The National Natural Science Foundation of China (No. 81172372)". We would like to acknowledge the reviewers for their helpful comments on this paper.

\section{References}

[1] Ebert, M.S. and Sharp, P.A. (2012) Roles for microRNAs in Conferring Robustness to Biological Processes. Cell, 149, 515-524. https://doi.org/10.1016/j.cell.2012.04.005

[2] Fabian, M.R. and Sonenberg, N. (2012) The Mechanics of miRNA-Mediated Gene Silencing: A Look under the Hood of miRISC. Nature Structural \& Molecular Biology, 19, 586593. https://doi.org/10.1038/nsmb.2296

[3] Dykxhoorn, D.M. (2010) MicroRNAs and Metastasis: Little RNAs Go a Long Way. Cancer Research, 70, 6401-6406. https://doi.org/10.1158/0008-5472.CAN-10-1346

[4] Lu, J., Getz, G., Miska, E.A., Alvarez-Saavedra, E., Lamb, J., Peck, D., Sweet-Cordero, A., Ebert, B.L., Mak, R.H., Ferrando, A.A., Downing, J.R., Jacks, T., Horvitz, H.R. and Golub, T.R. (2005) MicroRNA Expression Profiles Classify Human Cancers. Nature, 435, 834-838. https://doi.org/10.1038/nature03702

[5] Kumar, M.S., Lu, J., Mercer, K.L., Golub, T.R. and Jacks, T. (2007) Impaired microRNA Processing Enhances Cellular Transformation and Tumorigenesis. Nature Genetics, 39, 673-677. https://doi.org/10.1038/ng2003

[6] Shastry, B.S. (2009) SNPs: Impact on Gene Function and Phenotype. Methods in Molecular Biology, 578, 3-22. https://doi.org/10.1007/978-1-60327-411-1_1

[7] Ryan, B.M., Robles, A.I. and Harris, C.C. (2010) Genetic Variation in microRNA Networks: The Implications for Cancer Research. Nature Reviews Cancer, 10, 389-402. https://doi.org/10.1038/nrc2867

[8] Hu, Z., Chen, J., Tian, T., Zhou, X., Gu, H., Xu, L., Zeng, Y., Miao, R., Jin, G., Ma, H., Chen, Y. and Shen, H. (2008) Genetic Variants of miRNA Sequences and Non-Small Cell Lung 
Cancer Survival. The Journal of Clinical Investigation, 118, 2600-2608.

[9] Hoffman, A.E., Zheng, T., Yi, C., Leaderer, D., Weidhaas, J., Slack, F., Zhang, Y., Paranjape, T. and Zhu, Y. (2009) microRNA miR-196a-2 and Breast Cancer: A Genetic and Epigenetic Association Study and Functional Analysis. Cancer Research, 69, 5970-5977. https://doi.org/10.1158/0008-5472.CAN-09-0236

[10] Mittal, R.D., Gangwar, R., George, G.P., Mittal, T. and Kapoor, R. (2011) Investigative Role of Pre-microRNAs in Bladder Cancer Patients: A Case-Control Study in North India. DNA and Cell Biology, 30, 401-406. https://doi.org/10.1089/dna.2010.1159

[11] Stang, A. (2010) Critical Evaluation of the Newcastle-Ottawa Scale for the Assessment of the Quality of Nonrandomized Studies in Meta-Analyses. European Journal of Epidemiology, 25, 603-605. https://doi.org/10.1007/s10654-010-9491-z

[12] Christensen, B.C., Avissar-Whiting, M., Ouellet, L.G., Butler, R.A., Nelson, H.H., Mcclean, M.D., Marsit, C.J. and Kelsey, K.T. (2010) Mature microRNA Sequence Polymorphism in MIR196A2 Is Associated with Risk and Prognosis of Head and Neck Cancer. Clinical Cancer Research: An Official Journal of the American Association for Cancer Research, 16, 3713-3720. https://doi.org/10.1158/1078-0432.CCR-10-0657

[13] Li, X.D., Li, Z.G., Song, X.X. and Liu, C.F. (2010) A Variant in microRNA-196a2 Is Associated with Susceptibility to Hepatocellular Carcinoma in Chinese Patients with Cirrhosis. Pathology, 42, 669-673. https://doi.org/10.3109/00313025.2010.522175

[14] Liu, Z., Li, G., Wei, S., Niu, J., El-Naggar, A.K., Sturgis, E.M. and Wei, Q. (2010) Genetic Variants in Selected Pre-microRNA Genes and the Risk of Squamous Cell Carcinoma of the Head and Neck. Cancer, 116, 4753-4760. https://doi.org/10.1002/cncr.25323

[15] Okubo, M., Tahara, T., Shibata, T., Yamashita, H., Nakamura, M., Yoshioka, D., Yonemura, J., Ishizuka, T., Arisawa, T. and Hirata, I. (2010) Association between Common Genetic Variants in Pre-microRNAs and Gastric Cancer Risk in Japanese Population. Helicobacter, 15, 524-531. https://doi.org/10.1111/j.1523-5378.2010.00806.x

[16] Peng, S., Kuang, Z., Sheng, C., Zhang, Y., Xu, H. and Cheng, Q. (2010) Association of MicroRNA-196a-2 Gene Polymorphism with Gastric Cancer Risk in a Chinese Population. Digestive Diseases and Sciences, 55, 2288-2293. https://doi.org/10.1007/s10620-009-1007-x

[17] Qi, P., Dou, T.H., Geng, L., Zhou, F.G., Gu, X., Wang, H. and Gao, C.F. (2010) Association of a Variant in MIR 196A2 with Susceptibility to Hepatocellular Carcinoma in Male Chinese Patients with Chronic Hepatitis B Virus Infection. Human Immunology, 71, 621-626. https://doi.org/10.1016/j.humimm.2010.02.017

[18] Srivastava, K., Srivastava, A. and Mittal, B. (2010) Common Genetic Variants in Pre-MicroRNAs and Risk of Gallbladder Cancer in North Indian Population. Journal of Human Genetics, 55, 495-499. https://doi.org/10.1038/jhg.2010.54

[19] Wang, K., Guo, H., Hu, H., Xiong, G., Guan, X., Li, J., Xu, X., Yang, K. and Bai, Y. (2010) A Functional Variation in Pre-MicroRNA-196a Is Associated with Susceptibility of Esophageal Squamous Cell Carcinoma Risk in Chinese Han. Biomarkers, 15, 614-618. https://doi.org/10.3109/1354750X.2010.505299

[20] Akkiz, H., Bayram, S., Bekar, A., Akgollu, E. and Ulger, Y. (2011) A Functional Polymorphism in Pre-MicroRNA-196a-2 Contributes to the Susceptibility of Hepatocellular Carcinoma in a Turkish Population: A Case-Control Study. Journal of Viral Hepatitis, 18, e399e407. https://doi.org/10.1111/j.1365-2893.2010.01414.x

[21] Zhan, J.F., Chen, L.H., Chen, Z.X., Yuan, Y.W., Xie, G.Z., Sun, A.M. and Liu, Y. (2011) A Functional Variant in MicroRNA-196a2 Is Associated with Susceptibility of Colorectal Cancer in a Chinese Population. Archives of Medical Research, 42, 144-148. https://doi.org/10.1016/j.arcmed.2011.04.001 
[22] Zhang, X.P.S., Feng, Y., Liu, J. and Dong, J. (2011) Relationship between Genetic Polymorphism in MicroRNAs Precursor and Genetic Predisposition of Hepatocellular Carcinoma. Chinese Journal of Preventive Medicine, 45, 239-243.

[23] Chen, H., Sun, L.Y., Chen, L.L., Zheng, H.Q. and Zhang, Q.F. (2012) A Variant in MicroRNA-196a2 Is Not Associated with Susceptibility to and Progression of Colorectal Cancer in Chinese. Internal Medicine Journal, 42, e115-e119. https://doi.org/10.1111/j.1445-5994.2011.02434.x

[24] Chu, Y.H., Tzeng, S.L., Lin, C.W., Chien, M.H., Chen, M.K. and Yang, S.F. (2012) Impacts of MicroRNA Gene Polymorphisms on the Susceptibility of Environmental Factors Leading to Carcinogenesis in Oral Cancer. PLoS ONE, 7, e39777. https://doi.org/10.1371/journal.pone.0039777

[25] Hezova, R., Kovarikova, A., Bienertova-Vasku, J., Sachlova, M., Redova, M., Vasku, A., Svoboda, M., Radova, L., Kiss, I., Vyzula, R. and Slaby, O. (2012) Evaluation of SNPs in miR-196-a2, miR-27a and miR-146a as Risk Factors of Colorectal Cancer. World Journal of Gastroenterology, 18, 2827-2831. https://doi.org/10.3748/wjg.v18.i22.2827

[26] Kim, W.H., Min, K.T., Jeon, Y.J., Kwon, C.I., Ko, K.H., Park, P.W., Hong, S.P., Rim, K.S., Kwon, S.W., Hwang, S.G. and Kim, N.K. (2012) Association Study of MicroRNA Polymorphisms with Hepatocellular Carcinoma in Korean Population. Gene, 504, 92-97. https://doi.org/10.1016/j.gene.2012.05.014

[27] Min, K.T., Kim, J.W., Jeon, Y.J., Jang, M.J., Chong, S.Y., Oh, D. and Kim, N.K. (2012) Association of the miR-146aC>G, 149C>T, 196a2C > T, and 499A > G Polymorphisms with Colorectal Cancer in the Korean Population. Molecular Carcinogenesis, 51, E65-E73. https://doi.org/10.1002/mc.21849

[28] Zhu, L., Chu, H., Gu, D., Ma, L., Shi, D., Zhong, D., Tong, N., Zhang, Z. and Wang, M. (2012) A Functional Polymorphism in miRNA-196a2 Is Associated with Colorectal Cancer Risk in a Chinese Population. DNA and Cell Biology, 31, 350-354. https://doi.org/10.1089/dna.2011.1348

[29] Ahn, D.H., Rah, H., Choi, Y.K., Jeon, Y.J., Min, K.T., Kwack, K., Hong, S.P., Hwang, S.G. and Kim, N.K. (2013) Association of the miR-146aC>G, miR-149T $>$ C, miR-196a2T $>$ C, and miR-499A>G Polymorphisms with Gastric Cancer Risk and Survival in the Korean Population. Molecular Carcinogenesis, 52, E39-E51. https://doi.org/10.1002/mc.21962

[30] Dikeakos, P., Theodoropoulos, G., Rizos, S., Tzanakis, N., Zografos, G. and Gazouli, M. (2014) Association of the miR-146aC $>$ G, miR-149T $>$ C, and miR-196a2T $>C$ Polymorphisms with Gastric Cancer Risk and Survival in the Greek Population. Molecular Biology reports, 41, 1075-1080. https://doi.org/10.1007/s11033-013-2953-0

[31] Vinci, S., Gelmini, S., Mancini, I., Malentacchi, F., Pazzagli, M., Beltrami, C., Pinzani, P. and Orlando, C. (2013) Genetic and Epigenetic Factors in Regulation of MicroRNA in Colorectal Cancers. Methods, 59, 138-146. https://doi.org/10.1016/j.ymeth.2012.09.002

[32] Wang, S., Tao, G., Wu, D., Zhu, H., Gao, Y., Tan, Y., Wang, M., Gong, W., Zhou, Y., Zhou, J. and Zhang, Z. (2013) A Functional Polymorphism in MIR196A2 Is Associated with Risk and Prognosis of Gastric Cancer. Molecular Carcinogenesis, 52, E87-E95.

https://doi.org/10.1002/mc.22017

[33] Wei, J., Zheng, L., Liu, S., Yin, J., Wang, L., Wang, X., Shi, Y., Shao, A., Tang, W., Ding, G., Liu, C., Chen, S. and Gu, H. (2013) MiR-196a2 rs11614913T>C Polymorphism and Risk of Esophageal Cancer in a Chinese Population. Human Immunology, 74, 1199-1205. https://doi.org/10.1016/j.humimm.2013.06.012

[34] Chu, Y.H., Hsieh, M.J., Chiou, H.L., Liou, Y.S., Yang, C.C., Yang, S. and Kuo, W.H. (2014) MicroRNA Gene Polymorphisms and Environmental Factors Increase Patient Susceptibili- 
ty to Hepatocellular Carcinoma. PLoS ONE, 9, e89930.

https://doi.org/10.1371/journal.pone.0089930

[35] Kou, J.T., Fan, H., Han, D., Li, L., Li, P., Zhu, J., Ma, J., Zhang, Z.H. and He, Q. (2014) Association between Four Common MicroRNA Polymorphisms and the Risk of Hepatocellular Carcinoma and HBV Infection. Oncology Letters, 8, 1255-1260.

[36] Kupcinskas, J., Wex, T., Link, A., Leja, M., Bruzaite, I., Steponaitiene, R., Juzenas, S., Gyvyte, U., Ivanauskas, A., Ancans, G., Petrenkiene, V., Skieceviciene, J., Kupcinskas, L. and Malfertheiner, P. (2014) Gene Polymorphisms of MicroRNAs in Helicobacter Pylori-Induced High Risk Atrophic Gastritis and Gastric Cancer. PLOS ONE, 9, e87467. https://doi.org/10.1371/journal.pone.0087467

[37] Pu, J., Dong, W., Zhang, L., Liang, W.B., Yang, Y. and Lv, M.L. (2014) No Association between Single Nucleotide Polymorphisms in Pre-Mirnas and the Risk of Gastric Cancer in Chinese Population. Iranian Journal of Basic Medical Sciences, 17, 128-133.

[38] Qi, J.H., Wang, J., Chen, J., Shen, F., Huang, J.T., Sen, S., Zhou, X. and Liu, S.M. (2014) High-Resolution Melting Analysis Reveals Genetic Polymorphisms in MicroRNAs Confer Hepatocellular Carcinoma Risk in Chinese Patients. BMC Cancer, 14, 643. https://doi.org/10.1186/1471-2407-14-643

[39] Zhang, J., Wang, R., Ma, Y.Y., Chen, L.Q., Jin, B.H., Yu, H., Wang, J.C., Gao, C.F. and Liu, J. (2013) Association between Single Nucleotide Polymorphisms in miRNA196a-2 and miRNA146a and Susceptibility to Hepatocellular Carcinoma in a Chinese Population. Asian Pacific Journal of Cancer Prevention, 14, 6427-6431. https://doi.org/10.7314/APJCP.2013.14.11.6427

[40] Zhou, B., Dong, L.P., Jing, X.Y., Li, J.S., Yang, S.J., Wang, J.P. and Zhao, L.F. (2014) Association between miR-146aG $>C$ and miR-196a2C>T Polymorphisms and the Risk of Hepatocellular Carcinoma in a Chinese Population. Tumor Biology, 35, 7775-7780. https://doi.org/10.1007/s13277-014-2020-Z

[41] Li, X., Li, K. and Wu, Z. (2015) Association of four Common SNPs in MicroRNA Polymorphisms with the Risk of Hepatocellular Carcinoma. International Journal of Clinical and Experimental Pathology, 8, 9560-9566.

[42] Shen, F., Chen, J., Guo, S., Zhou, Y., Zheng, Y., Yang, Y., Zhang, J., Wang, X., Wang, C., Zhao, D., Wang, M., Zhu, M., Fan, L., Xiang, J., Xia, Y., Wei, Q., Jin, L., Wang, J. and Wang, M. (2016) Genetic Variants in miR-196a2 and miR-499 Are Associated with Susceptibility to Esophageal Squamous Cell Carcinoma in Chinese Han Population. Tumor Biology, 37, 4777-4784. https://doi.org/10.1007/s13277-015-4268-3

[43] Sushma, P.S., Jamil, K., Kumar, P.U., Satyanarayana, U., Ramakrishna, M. and Triveni, B. (2015) Genetic Variation in MicroRNAs and Risk of Oral Squamous Cell Carcinoma in South Indian Population. Asian Pacific Journal of Cancer Prevention, 16, 7589-7594. https://doi.org/10.7314/APJCP.2015.16.17.7589

[44] Ruan, K., Fang, X. and Ouyang, G. (2009) MicroRNAs: Novel Regulators in the Hallmarks of Human Cancer. Cancer Letters, 285, 116-126. https://doi.org/10.1016/j.canlet.2009.04.031

[45] Tong, N., Xu, B., Shi, D., Du, M., Li, X., Sheng, X., Wang, M., Chu, H., Fang, Y., Li, J., Wu, D. and Zhang, Z. (2014) Hsa-miR-196a2 Polymorphism Increases the Risk of Acute Lymphoblastic Leukemia in Chinese Children. Mutation Research, 759, 16-21. https://doi.org/10.1016/j.mrfmmm.2013.11.004

[46] Du, M., Lu, D., Wang, Q., Chu, H., Tong, N., Pan, X., Qin, C., Yin, C., Wang, M. and Zhang, Z. (2014) Genetic Variations in MicroRNAs and the Risk and Survival of Renal Cell Cancer. Carcinogenesis, 35, 1629-1635. https://doi.org/10.1093/carcin/bgu082 
[47] Guo, J., Jin, M., Zhang, M. and Chen, K. (2012) A Genetic Variant in miR-196a2 Increased Digestive System Cancer Risks: A Meta-Analysis of 15 Case-Control Studies. PLoS ONE, 7, e30585. https://doi.org/10.1371/journal.pone.0030585

[48] Tapia, T., Sanchez, A., Vallejos, M., Alvarez, C., Moraga, M., Smalley, S., Camus, M., Alvarez, M. and Carvallo, P. (2008) ATM Allelic Variants Associated to Hereditary Breast Cancer in 94 Chilean Women: Susceptibility or Ethnic Influences? Breast Cancer Research and Treatment, 107, 281-288. https://doi.org/10.1007/s10549-007-9544-5

Submit or recommend next manuscript to SCIRP and we will provide best service for you:

Accepting pre-submission inquiries through Email, Facebook, LinkedIn, Twitter, etc. A wide selection of journals (inclusive of 9 subjects, more than 200 journals)

Providing 24-hour high-quality service

User-friendly online submission system

Fair and swift peer-review system

Efficient typesetting and proofreading procedure

Display of the result of downloads and visits, as well as the number of cited articles

Maximum dissemination of your research work

Submit your manuscript at: http://papersubmission.scirp.org/

Or contact ojim@scirp.org 